\title{
ISPO-2013 Review. A Guest Editorial for a Special Edition of the Journal SILICON
}

\author{
Michael J. Owen
}

Received: 5 October 2014 / Accepted: 16 December 2014 / Published online: 13 January 2015

(C) Springer Science+Business Media Dordrecht 2015

The $9^{\text {th }}$ International Workshop on Silicon-Based Polymers was held at the A. N. Nesmeyanov Institute of Organoelement Compounds of the Russian Academy of Sciences (INEOS RAS) in Moscow on September 22-25, 2013. The workshop was chaired by Prof. Aziz M. Muzafarov, Director of INEOS RAS and a Member of the Russian Academy of Sciences. The International Advisory Board was composed of academic and industrial scientists from the USA, UK, Poland, Japan, Germany, Russia and France. The Local Organizing Committee was ably led by the workshop secretary, Aleksandra (Sasha) Bystrova. Previous workshops had been held in Ishikawa (Japan), Canterbury (UK), Troy (USA), Honolulu (Hawaii), Montpellier (France), Busan (Korea), and Lodz (Poland). Several of these meetings were held in conjunction with other relevant meetings. This $9^{\text {th }}$ workshop was immediately followed by the XII Andrianov Conference "Organosilicon Compounds, Synthesis, Properties, Applications". The working language of the Andrianov conference was Russian whereas that of the workshop was English.

The workshop was sponsored by the Russian Foundation for Basic Research, Dow Corning Corporation, Wacker Chemie AG, and Springer Science+Business Media. Although the weather was somewhat inclemental, the Russian hospitality was as warm as ever. Delegates had the opportunity to enjoy a guided tour of the Kremlin as well as a visit inside Lomonosov University, the largest of the Stalin-era skyscrapers known as the Seven Sisters. Another highlight was the conference dinner as we cruised down the Moscow River.

The technical program consisted of 13 invited lectures, 14 oral talks and 42 posters. The topics of the

M. J. Owen (两)

Michigan Molecular Institute, Midland, MI, USA invited lectures were functionalized polysiloxane microspheres (Julian Chojnowski), structured silicones (Michael Brook), new siloxane catalysts (Gregg Zank), silicon-based magnetic elastomers (Elena Kramarenko), conjugated organosilicon materials (Sergey Ponomorenko), coordination polymers containing organosilicon linkers (Paul Lickiss), functional polysiloxanes (Wlodzimierz Stanczyk), novel cage silsesquioxanes (Alan Bassindale), silicone resins (Dimi Katsoulis), ladder silsesquioxanes (Anna Kowalewska), cyclic silanols (Masafumi Unno), silicone surface science (Michael Owen) and silicon-based nanoparticles (Victor Timoshenko). These invited lectures were mostly devoted to siloxane-based polymers and materials. Scientific and technological interest continues in silsesquioxane polymers with several presentations on ladder and POSS structures. It was surprising that no different silicon-based backbone polymers such as polysilanes were featured. However, it does indicate that there is still much to learn and exploit regarding siloxane polymers.

The oral talks covered a wider range of synthesis, properties and applications of silicon-based polymers. Their topics were siloxane-containing polynorbornenes (Maria Gringolts), "self-healing" silicone additives (Francois Ganachaud), vinyl monomer polymerization in presence of silicone surfactants (Denis Shragin), highly gas permeable poly(3-trimethylsilyltricyclononene-7) and calixarenes (Maxim Bermeshev), ethoxysilanes synthesis (Jan Kurjata), silicon/alcohol direct synthesis (Andrey Zhitsov), disubstituted polyacetylenes (S. Matson), oligothiophenesilanes (Elena Agina), silicone contact lenses (Frances Lasowski), carbodiimide sol-gels (Edwin Kroke), click assembly of amphiphilic silicones (Talena Rambarran), novel electrical insulation and anti-corrosion materials (Stefan Pfeifer), supported rhodium hydrosilylation catalysts 
(Marek Cypryk) and siloxane-based polymer electrolytes (Jimi Aneli).

The poster presentations covered a similarly broad spectrum of silicon-containing polymer science. The most common themes were dendrimers and hyperbranched polymers, ladder and cage silsesquioxanes, metallasiloxanes, polycondensation, novel substituted organosiloxanes and nanoparticles and nanocomposites. At the end of the meeting four book prizes from the Springer "Advances in Silicon Science" series were presented to the following students: Talena Rambarren from McMaster University, Canada, for her talk on click chemistry, Andrey Zhitsov of INEOS RAS for his direct process presentation, Natalya Sheremetyeva of the Institute of Synthetic Polymer Materials RAS for her poster on carbosilane dendrimers and Maria Nowacka, Polish Academy of Sciences, for her three posters, two on ladder silsesquioxanes and one on new tetrafunctional cyclosiloxanolates.

This issue of SILICON contains a selection of these contributions from the workshop. Looking to the future, Francois Ganachaud has invited participants and all other interested members of the silicon-based polymer community to attend the next workshop which will be held at the CNRS Centre Paul Langevin in Aussois, France in April 2015. Francois was the organizer of the fifth workshop in Montpellier, France in 2007. 